This item was submitted to Loughborough's Research Repository by the author.

Items in Figshare are protected by copyright, with all rights reserved, unless otherwise indicated.

\title{
The cultural impact of workflow management systems in the financial
} services sector

PLEASE CITE THE PUBLISHED VERSION

http://dx.doi.org/10.1080/714005046

PUBLISHER

Routledge

VERSION

AM (Accepted Manuscript)

LICENCE

CC BY-NC-ND 4.0

REPOSITORY RECORD

Doherty, Neil, and Ivor Perry. 2019. "The Cultural Impact of Workflow Management Systems in the Financial Services Sector”. figshare. https://hdl.handle.net/2134/8345. 
This item was submitted to Loughborough's Institutional Repository (https://dspace.lboro.ac.uk/) by the author and is made available under the following Creative Commons Licence conditions.

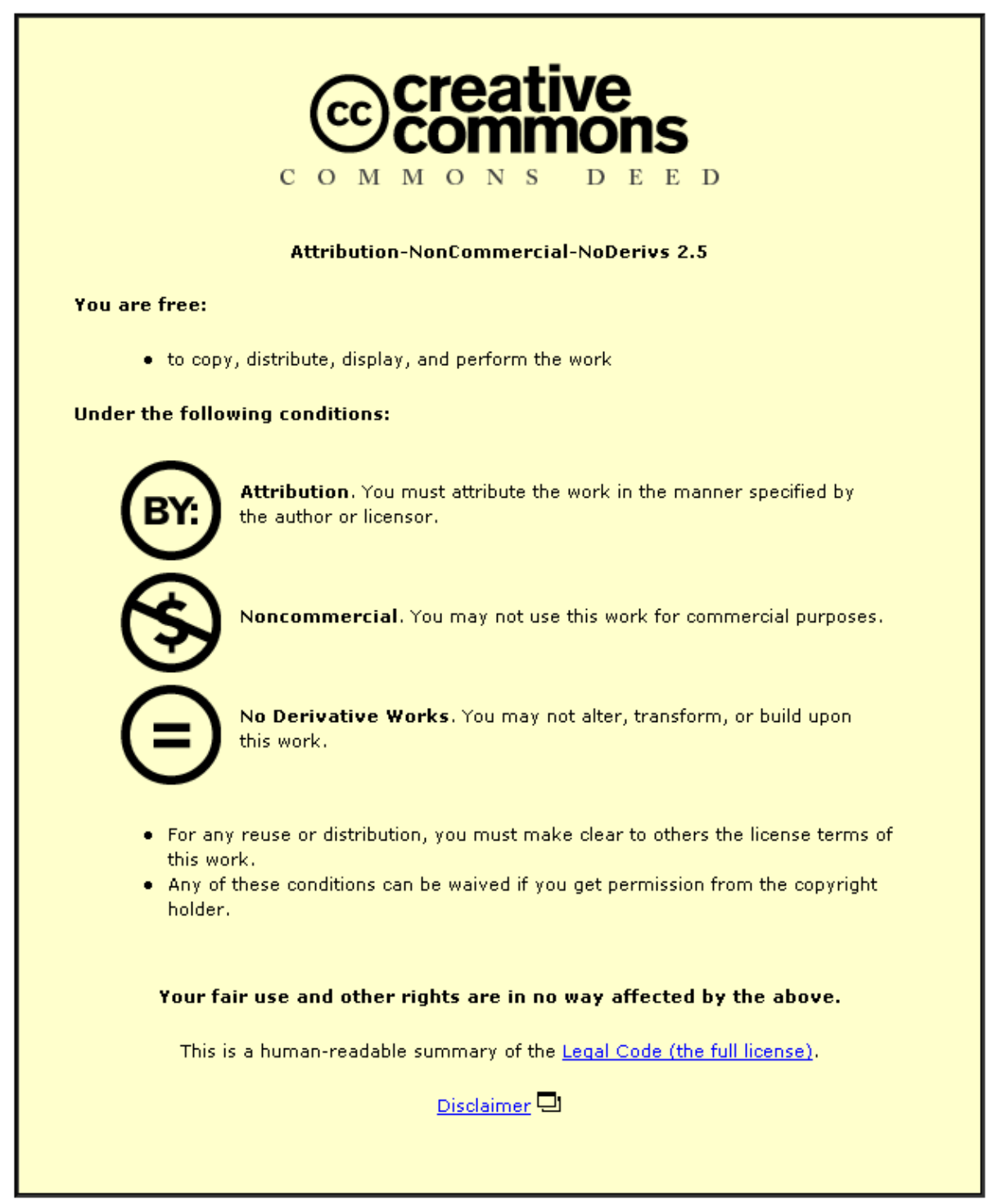

For the full text of this licence, please go to: http://creativecommons.org/licenses/by-nc-nd/2.5/ 


\section{Loughborough University}

\section{The Cultural Impact of Workflow Management Systems in the Financial Services Sector}

Neil F. Doherty - The Business School, Loughborough University
Ivor Perry - The Department of Information Systems, De Montfort University

Abstract: The implementation of information systems is increasingly resulting in significant changes to the host organisation's culture. In particular, the workflow management system (WFMS) is one new technology that, because of its tendency to have a direct impact on the organisation and execution of work, has the potential to significantly modify an organisation's culture. This qualitative research investigates the nature of the relationship between WFMS and organisational culture, in the UK financial services sector The research concludes that WFMS have the potential to modify culture in a positive way by improving the organisations customer orientation, flexibility and quality focus. 


\section{Introduction}

Organisations of all shapes and sizes have to enthusiastically embrace information technology if they wish to survive, and hopefully thrive, in an increasingly competitive environment. In the past information systems were primarily developed to support the administrative functions within a business, by simply automating existing processes, without fundamentally changing the way in which an organisation operated. The current trend is for information systems which are highly integrated, have the ability to disseminate information throughout an organisation, and often have become an integral part of the actual product or service provided. Such trends mean that IT now has a profound impact on almost every aspect of the way in which organisations conduct their business. For example, one area where IT has been found to have a particularly significant impact is with respect to an organisation's culture [Butterfield \& Pendegraft, 1996; Pliskin et al, 1993; Romm et al, 1991; Walton, 1989].

An interesting example of an emergent technology that has the potential to modify organisational culture is the workflow management system (WFMS), as it seeks to automate the storage, processing and distribution of documents, and in so doing radically re-engineer clerical and administrative operations [Amberg, 1996]. This paper, therefore, seeks to investigate the impact that the introduction of WFMS technology on an organisation's culture. More specifically, this paper: summarises the literature appertaining to the cultural impact of information technology; describes a research project to investigate the cultural impact of WFMS; and critically appraises the results of the research. Finally, the lessons that can be learned with regard to the alignment of IT and organisational culture in future systems development projects are discussed.

\section{Literature Review and Research Objectives}

The aim of this section is to present a discussion of the literature with regard to organisational culture, the impact of IT on corporate culture, and the characteristics of workflow management systems (WFMSs). In so doing, the academic justification for this research is established.

\section{Organisational Culture}

Academics typically define organisational culture in terms of the way people think, which has a direct influence on the ways in which they behave. For example, Williams et al [1990] and Sathe [1985] both describe culture in terms of shared and relatively stable 'assumptions, beliefs and values' that exist within an organisation. Organisational culture can therefore be viewed as the 'the social or normative glue that holds the organisation together' [Smircich, 1983]. Whilst accepting these definitions, in principle, it is important to make two caveats. Firstly, it has been recognised that as organisations grow it is likely that a number of subcultures, based upon functions or teams, will proliferate as opposed to the existence of one all pervading culture shared by the entire organisation [Zammuto \& Krakower, 1991]. Secondly, although culture is usually considered to be relatively stable, in practice they evolve over time in response to changes in the internal and external environments [Brown, 1998: 193]. 
Many management gurus, in particular Peters and Waterman [1980: xxii] have vigorously promoted the idea of developing a 'strong' corporate culture, as a mechanism for improving organisational effectiveness and ultimately financial performance. As Willmott [1993: 513] notes 'ideas about the strengthening of Corporate Culture now infuse diverse corporate change programmes, including those introduced primarily as a means of improving quality, flexibility and or responsiveness to customer needs'. Consequently, there is now a common management perception 'of culture as a manipulable variable for gaining competitive advantage' [Willmott, 1993: 518], which has brought organisational culture to the forefront of much management thinking. The view that organisation culture is something that can be manipulated to promote organisational effectiveness, has increased the need for methods and strategies that can be used to effectively manage cultural change [Williams et al, 1990: 65-83]. Unfortunately, cultural change typically brings considerable uncertainty, with employees feeling that their job security or status is under threat [Furnham \& Gunter, 1993]. Consequently, it is important that cultural change programmes explicitly recognise the likelihood of resistance to change and take effective steps to counteract the threat [Williams et al, 1990: 91].

\section{Information Technology and Cultural Change}

Because information technology is playing an increasingly important role in the operations and strategic direction of an organisation, it is inevitably becoming a significant catalyst for the planned or unplanned re-shaping of organisational culture [Stowell \& West, 1994; Walton, 1989]. This is particularly the case where IT is being used to facilitate the reengineering or fundamental transformation of organisations [Moreton \& Chester, 1996: 43]. However, as Pliskin et al [1993] have discovered, problems occur when implementing systems where the assumptions about organisational culture built into an information system are at odds with the actual culture of the host organisation. They suggest that this type of mis-alignment between information systems and organisational culture will almost inevitably result in a problematical systems implementation, or even a total rejection of the system. The findings of Plisken et al [1993] are supported by Cooper [1993] who suggests that when IT conflicts with an organisation's culture, the implementation will be resisted in one of two ways; either the system will be rejected or modified so that it matches the existing culture. This puts the systems developer in something of a 'catch 22' situation in that IT is increasingly likely to precipitate cultural change, but this may in turn increase the chances of a problematic implementation or even outright systems rejection. One potential solution to this dilemma is offered by Butterfield \& Pendegraft [1996] who advocate the explicit management of the cultural change through the completion of a formal cultural analysis during the systems development process to avoid cultural conflict later.

\section{Workflow Management Systems Concepts}

Workflow management systems hold the promise of supporting, and enhancing, the day to day operations of many businesses and work environments, and as a result many organisations are now already using, or actively evaluating, the technology. A workflow has been defined by the Workflow Management coalition as the automation of a business process, in whole or part, during which documents, information or tasks are passed from one participant to another for action, according to a set of procedural rules' [Lawrence, 1997: 
385]. Furthermore, they define a workflow management systems as 'the software components used to interpret process definitions, create and manage workflow instances as they are executed, and control their interaction with workflow participants and applications' [Lawrence, 1997: 387]. The workflow is therefore the automated process, whilst the workflow management system is the software that manages the automation of an integrated set of processes. Although the technology is still only in its infancy there is growing evidence that its commercial impact is likely to be highly significant [Amberg, 1996], because it has the potential to enhance the flexibility, efficiency and customer orientation of companies.

The best way to demonstrate the capabilities of this technology is through an example. Sprague and McNurlin [1993: 496], for example, present the case of the Diners Club, who have applied WFMS technology in a very typical way. All paperwork with regard to credit card transactions is now routinely scanned and digitised. Consequently, whenever a Diners Club card holder rings to query a specific transaction or charge on their monthly statement, the system-user handling the call can immediately get a copy of the relevant source documents on the screen, and in most cases resolve the problem immediately. Since the system tracks and routes the work, the company representatives now spend their time studying cases and making decisions rather than chasing paper.

The automation of clerical and administrative procedures, turning offices into 'paper factories', will inevitably have a significant organisational impact, radically changing working practices, job descriptions and the way in which employees interrelate. As definitions of organisational culture have typically related to 'how work is done and how people relate to one another' [Furnham \& Gunter, 1993], it is also likely the introduction of WFMS will have a significant impact on organisational culture. It is, therefore, important that research is conducted to investigate the nature of this organisational impact and the managerial implications of this increasingly significant technology.

\section{Summary of Literature}

In summary the literature suggests that, although often highly desirable, employees' natural resistance to change will often impede attempts to modify an organisation's culture. In particular it has been shown that the cultural change engendered by the introduction of IT may well result in high levels of user resistance. On a more positive note, there is also evidence that well planned cultural change programmes, which explicitly recognise the concerns of employees, are more likely to succeed. From this summary of the literature, it can therefore be hypothesised that organisationally intrusive technologies such as WFMS will have a significant impact upon organisation culture, which unless managed appropriately is likely to result in user resistance. The above discussion of the literature allows us to propose the three following important research objectives that have provided the focus for the research project presented in this paper:

- To investigate the nature of the cultural change engendered through the introduction of WFMS technology.

2 To explore the implications of any IT-induced cultural change.

3 To review the incidence, and effectiveness, of any explicit strategies that have been adopted to manage the cultural change process. 
It was envisaged that the exploration of these objectives might provide some important insights into the management of IT-induced cultural change in general, and the implications for organisations operating in the financial services sector in particular.

\section{Research Method}

The aim of this section is to describe the method employed for exploring the three research issues highlighted at the end of the previous section. Due to the lack of prior empirical research in this area, an exploratory research design was chosen, as 'it is appropriate to any problem about which little is known' [Churchill, 1995: 149]. More specifically, the research objectives were explored primarily by adopting a multiple case study approach [Yin, 1994: 44], in which the semi-structured interview was the primary instrument for data collection. However, in order to provide a broad overview and to aid in focussing the research objectives a preliminary survey was also conducted. The remainder of this section describes the initial piece of survey research, and then outlines the design, validation and execution of the qualitative research instrument that was used to investigate the research objectives in far more detail.

\section{The Contribution of the Preliminary Survey Research}

As the viability of this research project was predicated upon the assumption that the introduction of WFMS would modify an organisation's culture, it was important to clarify this issue at the earliest possible opportunity. The preliminary survey was therefore used as a mechanism for explicitly testing this hypothesis. Furthermore, the survey was of great assistance in the identification of an appropriate segment, and willing participants, to target for the interview phase of the research. The survey was targeted at members of the UserNet group, which is a forum for representatives of organisations who are active users of the WFMS software FileNet. The targeting of FileNet users was a sensible choice, given that the findings of a recent Conspectus report [1996] indicated that FileNet is the dominant supplier of this emergent technology with a 30\% market share. The UserNet annual general meeting was chosen as the mechanism for distributing the questionnaires, as it is always very well attended and the organisers were happy to promote the importance of the study. Questionnaires were distributed to all of the 59 delegates, and a total of 30 usable responses were collected, giving a very creditable response rate of just over $50 \%$. Despite the high response rate, the possibility of non-response bias [Churchill, 1995 p.] must be acknowledged, as there was no easy way to canvass the views of the 29 non-respondents.

The results of the survey confirmed the first research objective, indicating that in many cases the implementation of WFMS technology has a direct impact on organisational culture. Of the 30 responses collected, 23 respondents (77\%) confirmed that the implementation of a WFMS within their organisation had a noticeable impact on organisational culture. Furthermore, it was found that the cultural change had only been planned for or anticipated in advance of the system's implementation in 52\% of such cases. These results were encouraging as they confirmed that there would be plenty of candidates with whom to discuss the implications of cultural change, in both its planned and un-planned forms. In 
order to make the research results easier to interpret, another major objectives of the initial survey had been to identify a clearly bounded segment to target for follow-up interviews. From the total of 30 responses well over half came from organisations operating in the financial services sector, which covers banking, finance and insurance. Consequently, as the initial survey had only been aimed at FileNet users, the chosen segment for interviews was managers, all working in companies operating in the financial services sector, who were actively involved in the development of WFMSs based upon FileNet technology.

\section{$\underline{\text { Interview Design and Validation }}$}

The structured interview format was chosen, for data collection purposes, as researchers were fairly confident about the issues they wished to explore, having conducted the initial survey. Furthermore it was felt the structured format would allow for direct comparisons to be made between the views of different respondents. The interview questions were initially based upon issues raised in the literature, and issues highlighted by the results of the initial survey. It was particularly important, for example, that the assertions about the cultural impact of WFMS collected from the survey could be substantiated through the collection of evidence and specific examples during the interview stage. Having developed an interview script, it was thoroughly validated by undertaking three pre-test interviews with appropriate professionals. These validation sessions proved to be very useful in that not only did they give the researchers confidence that they were tackling an important and interesting area of research, but also helped to identify a number of weaknesses in the initial interview design. Whilst the interview script ultimately employed is far too long (12 sides of A4) to present in full, a summarised version of the sections of the interview script relating to WFMS and culture is presented in appendix $A$.

In designing the interview script the importance of establishing a common vocabulary for discussing organisational culture was recognised. Consequently, the following definition of organisational culture was used throughout the study: 'the set of assumptions, beliefs and values, often un-stated, that members of an organisation share in common' [Sathe, 1985]. Whilst this definition proved a useful starting point for discussing organisational culture, it was also necessary to review the specific dimensions of culture that might have been modified. Ultimately, the list of cultural dimensions, as presented in table 1, was used throughout the project as the common basis for establishing the nature of any cultural change.

\section{$\underline{\text { Interview Targeting and Execution }}$}

As noted earlier, the qualitative phase of the research sought to target managers, from the financial services sector, with a significant involvement in, and responsibility for, the development and operation of a WFMS. The preliminary questionnaire was used as a mechanism to identify managers, from the financial sector, willing to participate in the interviews. Fortunately, the 16 managers who volunteered to participate, formed a wellbalanced sample, as they represented organisations that had experienced planned cultural change, unplanned cultural change and no cultural change. Of these, 12 individuals were invited to participate in full-length interviews, which lasted approximately one hour, as they represented organisations that had experienced cultural change. The remaining four 
managers participated in shorter interviews, approximately 20-30 minutes, as their organisations had not experienced cultural change. In most cases the interviews, whether short or long, were supported by follow up phone calls to clarify issues. It can be seen from the summary of the interviewees, as presented in table 2, that the vast majority of the full interviews were conducted with project managers, either with overall project responsibility, or with responsibility for the business or the technical aspects of the project.

Table 1: Dimensions of Organisational Culture

\begin{tabular}{ll}
\hline Dimensions & Source \\
\hline Innovation and action orientation & Pliskin et al (1993) \\
Risk taking & Pliskin et al (1993) \\
Integration and lateral independence & Pliskin et al (1993) \\
Top management contact & Pliskin et al (1993) \\
Autonomy in decision-making (empowerment) & Pliskin et al (1993) \\
Reward orientation & Pliskin et al (1993) \\
Performance orientation & Pliskin et al (1993) \\
Focus on customer service & Willmott (1993) \\
Focus on quality & Willmott (1993) \\
Focus on flexibility & Willmott (1993) \\
Team-working & Pre-testing Exercise \\
\hline
\end{tabular}

Table 2: Interviewee Details

\begin{tabular}{cll}
\hline Interview No. & Organisation Type & Position \\
\hline 1 & Insurance & Project Manager \\
2 & Insurance & Project Manager \\
3 & Bank & Business Project Manager \\
4 & Building Society & Project Manager \\
5 & Bank & Business Project Manager \\
6 & Insurance & IT Project Manager \\
7 & Building Society & Project Manager \\
8 & Bank & Business Project Manager \\
9 & Insurance & Senior Analyst \\
10 & Bank & Project Manager \\
11 & Building Society & Business Project Manager \\
12 & Insurance & Project Manager \\
13 & Bank & IT Project Manager \\
14 & Bank & IT Project Manager \\
15 & Bank & IT Project Manager \\
16 & Insurance & Business Project Manager \\
\hline
\end{tabular}




\section{Data Analysis Strategy}

The results of each interview were captured by using either a tape-recorder or pen and paper. Having conducted and the interview, the results were immediately written up in a standard format. The first stage of the data analysis exercise was to code the transcribed text. In general, the answers to the closed questions didn't require any further coding, as the data was already in a meaningful format. However, the answers to the open questions were coded to highlight patterns and themes. More specifically, 'in-vivo' codes (codes originating from the respondents themselves [Strauss \& Corbin, 1990]) were used to uniquely identify recurring themes, such as problems, solutions, impacts, effects or approaches, highlighted in the interviews. Whilst both the 'within-case' and 'cross-case' approaches [Miles and Huberman, 1994] were then used to further analyse the coded transcripts, this paper presents the results of the cross-case analysis, which identifies patterns across the cases. More specifically, the 'variable-oriented approach' [Runkel, 1990] to cross-case analysis was used to evaluate the levels of consensus or inconsistency that existed with respect to different issues.

\section{Research Results}

The most significant results of this research project have been summarised in a series of tables, whilst a more detailed discussion of the findings, including the results of supplementary questions, and a review of specific evidence and examples, is presented below. The majority of the evidence presented is based upon the 12 full interviews, but material from the other four interviews is also used where appropriate. To make the discussion more meaningful the research findings are related to the three specific research objectives, proposed earlier in this paper.

\section{The Nature of the Cultural Change}

The findings presented in Table 3 indicate that whilst there is some variability, with respect to the planning and anticipation of cultural change, its impact in all cases is localised, at least to start with. Moreover, the scope of the impact tends to be limited to all those employees who are either direct users of the system, or recipients of system generated information.

It is also interesting to note, from Table 3 that in nearly all cases the newly modified culture aligns strongly with the organisations espoused values, or an espoused culture. This tends to suggest that in many organisations the espoused values, as advocated by senior managers, are not sufficiently well promoted or understood by the workforce, in order to be adopted as their own values. When, however, a technology such as WFMS, which facilitates customer focus, flexibility etc., is adopted then a deeper cultural change may be precipitated. As one project manager (case 7) noted 'many of these changes have been on the agenda for some time, and WFMS simply provided an effective tool for realising them'. Another interviewee (10) suggested that: 'it took the sheer size of the investment in WFMS technology, and its associated organisational change, to ensure that there was the political will to turn espoused values into reality'. In summary, WFMS can be viewed as an essential catalyst for translating espoused cultural values into reality. The interviewees were also asked whether they 
believed that individual employees would recognise that their values and beliefs had been modified by the introduction of WFMS technology. The majority thought the individual user would agree, as one project manager (3) commented: 'the working atmosphere, in the affected team, is discernibly more positive than in all the others, with WFMS users being highly motivated, interested, organised and proud of their achievement'.

Table 3: A Summary of the most Significant Findings of the Cultural Impact of WFMS Technology

\begin{tabular}{|c|c|c|c|c|}
\hline & $\begin{array}{l}\text { Nature of } \\
\text { Impact }\end{array}$ & $\begin{array}{l}\text { Extent of } \\
\text { Impact }\end{array}$ & $\begin{array}{l}\text { Aligns with } \\
\text { espoused } \\
\text { culture }\end{array}$ & $\begin{array}{l}\text { Would users } \\
\text { agree that } \\
\text { values have } \\
\text { changed? }\end{array}$ \\
\hline 1 & $\begin{array}{l}\text { Unplanned, but anticipated, } \\
\text { cultural change. }\end{array}$ & $\begin{array}{l}\text { Impact local (all } \\
\text { users) }\end{array}$ & Yes, probably & $\begin{array}{l}\text { Probably } \\
\text { wouldn't see it } \\
\text { like that }\end{array}$ \\
\hline 2 & Planned cultural change. & $\begin{array}{l}\text { Impact local but } \\
\text { becoming global }\end{array}$ & Yes & Yes \\
\hline 3 & $\begin{array}{l}\text { Unplanned, but anticipated, } \\
\text { cultural change. }\end{array}$ & $\begin{array}{l}\text { Impact local but } \\
\text { becoming global }\end{array}$ & $\begin{array}{l}\text { Yes; for } \\
\text { business unit }\end{array}$ & Yes \\
\hline 4 & $\begin{array}{l}\text { Unplanned, and un- } \\
\text { anticipated, cultural change. }\end{array}$ & $\begin{array}{l}\text { Impact local (one } \\
\text { specific function) }\end{array}$ & Yes & Yes \\
\hline 5 & $\begin{array}{l}\text { Unplanned, but anticipated, } \\
\text { cultural change. }\end{array}$ & $\begin{array}{l}\text { Impact local (all } \\
\text { user depts.) }\end{array}$ & Yes & Yes \\
\hline 6 & $\begin{array}{l}\text { Unplanned and un-anticipated } \\
\text { cultural change. }\end{array}$ & $\begin{array}{l}\text { Impact local (all } \\
\text { users) }\end{array}$ & Yes & $\begin{array}{l}\text { In front office } \\
\text { definitely, other } \\
\text { areas less so. }\end{array}$ \\
\hline 7 & $\begin{array}{l}\text { Unplanned but anticipated } \\
\text { cultural change. }\end{array}$ & $\begin{array}{l}\text { Impact local (all } \\
\text { managers) }\end{array}$ & Yes & $\begin{array}{l}\text { Yes; on a small- } \\
\text { scale }\end{array}$ \\
\hline 8 & $\begin{array}{l}\text { Unplanned, but anticipated, } \\
\text { cultural change. }\end{array}$ & $\begin{array}{l}\text { Impact local (all } \\
\text { managers) }\end{array}$ & Yes & Yes \\
\hline 9 & $\begin{array}{l}\text { Unplanned and un-anticipated } \\
\text { cultural change. }\end{array}$ & $\begin{array}{l}\text { Impact local (user } \\
\text { function) }\end{array}$ & No & $\begin{array}{l}\text { Yes; they would } \\
\text { not go back to } \\
\text { old ways }\end{array}$ \\
\hline 10 & Planned cultural change. & $\begin{array}{l}\text { Impact local (all } \\
400 \text { users) }\end{array}$ & Yes & Yes \\
\hline 11 & Planned cultural change. & $\begin{array}{l}\text { Impact local } \\
\text { (product team) }\end{array}$ & Yes & Yes \\
\hline 12 & Planned cultural change. & $\begin{array}{l}\text { Impact local (all } \\
600 \text { users) }\end{array}$ & Yes & Yes \\
\hline
\end{tabular}

When it came to the specific dimensions of cultural change, interviewees were firstly asked to identify which they perceived to have been modified, see table 4 , and then to provide specific examples and evidence to support their assertions. All interviewees acknowledged that the application of workflow technology has facilitated a customer-focused culture within their organisation, department or work group. Typical comments included: 'users are now more aware, and very proactive, in managing customer service levels' (4) and 'there is now a strong belief that first rate customer service is paramount' (11). The next most commonly cited cultural change was with respect to flexibility. The application of workflow technologies has 'freed many constraints with respect to the way work is managed and organised' (1), which in turn promotes a 'commonality of approach that facilitates flexibility and the multi- 
skilling of the workforce' (3). Because of the increased visibility of processes employees have also become far more conscious of the quality of their contributions, and this strengthens the quality focus of the organisational culture; 'we used to have separate doers and checkers, now everyone is responsible for their own quality control' (9).

Table 4: A Summary of the dimensions of culture identified in each case.

\begin{tabular}{lccccccccccccc}
\hline Cultural Dimensions & $\mathbf{1}$ & $\mathbf{2}$ & $\mathbf{3}$ & $\mathbf{4}$ & $\mathbf{5}$ & $\mathbf{6}$ & $\mathbf{7}$ & $\mathbf{8}$ & $\mathbf{9}$ & $\mathbf{1 0}$ & $\mathbf{1 1}$ & $\mathbf{1 2}$ & Total \\
\hline Customer Focus & $\checkmark$ & $\checkmark$ & $\checkmark$ & $\checkmark$ & $\checkmark$ & $\checkmark$ & $\checkmark$ & $\checkmark$ & $\checkmark$ & $\checkmark$ & $\checkmark$ & $\checkmark$ & 12 \\
Flexibility & $\checkmark$ & $\checkmark$ & $\checkmark$ & $\checkmark$ & $\checkmark$ & $\checkmark$ & & & $\checkmark$ & $\checkmark$ & $\checkmark$ & $\checkmark$ & 10 \\
Quality Focus & $\checkmark$ & $\checkmark$ & $\checkmark$ & & $\checkmark$ & $\checkmark$ & & & $\checkmark$ & $\checkmark$ & & $\checkmark$ & 8 \\
Performance Orientation & & $\checkmark$ & $\checkmark$ & $\checkmark$ & $\checkmark$ & $\checkmark$ & $\checkmark$ & & & & & $\checkmark$ & 7 \\
Empowerment & & $\checkmark$ & $\checkmark$ & & $\checkmark$ & $\checkmark$ & & $\checkmark$ & & & $\checkmark$ & $\checkmark$ & 7 \\
Team-working & & $\checkmark$ & & & $\checkmark$ & & & & $\checkmark$ & $\checkmark$ & $\checkmark$ & & 5 \\
Integration & $\checkmark$ & & & & & & & & & $\checkmark$ & & & 3 \\
Innovation & $\checkmark$ & $\checkmark$ & & & & & & & & & & & \\
Totals & 5 & 7 & 5 & 3 & 6 & 5 & 3 & 2 & 4 & 6 & 4 & 5 & 53 \\
\hline
\end{tabular}

Other dimensions of the change to organisational culture were less widely recognised. However, a number of respondents suggested that there was a far stronger performance orientation present in the culture. This was largely due to the fact that the introduction of a WFMS makes the performance of functions, teams and individuals 'far more visible and consequently employees are far more conscious of their own personal contribution' (12). Furthermore, because system users have all the requisite information, to deal with queries in an effective and timely fashion, it is appropriate to empower them to decide how such queries should be progressed; 'decision-making is now devolved to those who are doing the work' (5). Finally, other dimensions of culture that were cited included team-working; 'users are now organised into highly flexible teams' (11); and integration; 'the affected departments now work more closely together than had been the case' (7). The only cultural dimension, not on the interview schedule, which was often mentioned was the transition to an information culture in which 'users are now pushing for more automation, they can't do without it' (9).

It was noted that many of the cultural changes cited above, are 'highly interconnected' (6). For example, the move towards a customer-orientated culture is greatly facilitated by the empowerment and flexibility dimensions of the cultural change. More specifically, it was suggested that customer focus is facilitated through: greater flexibility; which 'provides a single response point to multiple customer queries' (4); and the empowerment of users, which greatly reduces the number of 'hand-offs' $(\mathbf{1 0})$ in which the customer request has to be passed to a supervisor for authorisation.

Even in the four cases where respondents to the initial survey had indicated that there had been no cultural change, the results of the shorter follow-up interviews were still of interest. All of these individuals agreed that the introduction of WFMS technology was capable of 
inducing cultural change. Furthermore, they all recognised that cultural change was likely within their own organisations once the technology had either become more widespread or better established.

In conclusion much evidence was gathered to support the case that the introduction of WFMSs has led to changes in the culture of the host organisation. It must be remembered, when interpreting these results, that the research has focussed on the interviewees' perceptions of cultural change, primarily evidenced through changes in user behaviour, rather than attempting to explicitly measure changes in the 'assumptions, beliefs and values' of all the affected users. However, given that behavioural change is recognised to be the observable manifestation of a cultural change programme [Sathe, 1985; Thompson \& Luthens, 1990: 319-344; Williams et al, 1990: 12], it is reasonable to assume that the behavioural changes witnessed by the interviewees are a good indicator of a deeper cultural change.

\section{The Success of the Workflow Management Systems and the Cultural Change}

It can be seen from the findings, summarised in table 5, that all the interviewees perceived that the introduction of the WFMS, and its associated cultural change, had been perceived as making a positive contribution to organisational effectiveness. When asked about the specific nature of the realised benefits the vast majority of the interviewees ranked improvements to customer service as the most important, with improvements to productivity, reductions in cost, and improvements in quality also being frequently cited. Moreover, in all cases, except one (8), the interviewees were able to confirm that a formal evaluation exercise had been conducted, to support their perceptions. In the one instance where there was no explicit evaluation, the interviewee (8) claimed that: 'because the benefits were so self-evident, to all concerned' no appraisal was deemed necessary'. A fuller discussion of the benefits associated with the introduction of WFMS can be found in Doherty \& Perry [1998].

Whilst the success of the WFMS, and the success of the resultant cultural change, were readily acknowledged by the participating project managers, it could be that the perceptions, and attitudes, of the user community were less enthusiastic. Consequently, the interviewees were asked to comment on user attitudes to the system before and after its implementation. In most cases the respondents suggested a climate of general nervousness and scepticism within the user community, prior to systems development. However, by the time of implementation, and into the operational phase of the life cycle users attitudes were reported as being far more positive. Moreover, the majority of the interviewees were able to describe user attitude surveys that had been conducted before and after the implementation of the system, to substantiate their perceptions. These highly positive of user attitudes were attributed to very active user participation, and the realisation from the users that the technology upgraded, and broadened, their skills and made the job more interesting. 
Table 5: The success of WFMS and cultural change.

\begin{tabular}{|c|c|c|c|c|}
\hline $\begin{array}{l}\text { Case } \\
\text { no. }\end{array}$ & $\begin{array}{l}\text { Impact of } \\
\text { cultural } \\
\text { change }\end{array}$ & $\begin{array}{l}\text { Success of } \\
\text { WFMS project }\end{array}$ & $\begin{array}{l}\text { User } \\
\text { Attitudes to WFMS }\end{array}$ & $\begin{array}{l}\text { Cultural } \\
\text { change } \\
\text { programme }\end{array}$ \\
\hline 1 & Positive & $\begin{array}{l}\text { WFMS exceeded } \\
\text { expectations }\end{array}$ & $\begin{array}{l}\text { Attitudes reasonable at the outset. } \\
\text { Attitudes now more positive. }\end{array}$ & No \\
\hline 2 & Positive & $\begin{array}{l}\text { WFMS exceeded } \\
\text { expectations }\end{array}$ & $\begin{array}{l}\text { Users keen throughout project, } \\
\text { and still very positive. }\end{array}$ & No \\
\hline 3 & Positive & $\begin{array}{l}\text { WFMS exceeded } \\
\text { expectations }\end{array}$ & $\begin{array}{l}\text { Very sceptical at outset, now } \\
\text { wouldn't be without system }\end{array}$ & No \\
\hline 4 & Positive & $\begin{array}{l}\text { WFMS exceeded } \\
\text { expectations }\end{array}$ & Very positive all the way through & No \\
\hline 5 & Positive & $\begin{array}{l}\text { WFMS exceeded } \\
\text { expectations }\end{array}$ & $\begin{array}{l}\text { Users sceptical at outset of project, } \\
\text { very positive now }\end{array}$ & $\begin{array}{l}\text { Yes, explicit } \\
\text { programme }\end{array}$ \\
\hline 6 & Positive & $\begin{array}{l}\text { WFMS exceeded } \\
\text { expectations }\end{array}$ & $\begin{array}{l}\text { some concerns at outset of project } \\
\text { but now very positive }\end{array}$ & No \\
\hline 7 & Positive & $\begin{array}{l}\text { WFMS exceeded } \\
\text { expectations }\end{array}$ & $\begin{array}{l}\text { Mixed views at outset. More } \\
\text { positive by finish. }\end{array}$ & No \\
\hline 8 & Positive & $\begin{array}{l}\text { WFMS exceeded } \\
\text { expectations }\end{array}$ & $\begin{array}{l}\text { By the end of the project the } \\
\text { system was fully accepted by } \\
\text { users }\end{array}$ & No \\
\hline 9 & Positive & $\begin{array}{l}\text { WFMS exceeded } \\
\text { expectations }\end{array}$ & $\begin{array}{l}\text { Users sceptical at outset of project, } \\
\text { very positive now }\end{array}$ & No \\
\hline 10 & Positive & $\begin{array}{l}\text { WFMS exceeded } \\
\text { expectations }\end{array}$ & $\begin{array}{l}\text { Users resistant and frightened at } \\
\text { outset, now very positive }\end{array}$ & $\begin{array}{l}\text { Yes; an } \\
\text { implicit } \\
\text { programme }\end{array}$ \\
\hline 11 & Positive & $\begin{array}{l}\text { WFMS exceeded } \\
\text { expectations }\end{array}$ & $\begin{array}{l}\text { Extremely positive though-out } \\
\text { project }\end{array}$ & $\begin{array}{l}\text { Yes; an } \\
\text { implicit } \\
\text { programme }\end{array}$ \\
\hline 12 & Positive & $\begin{array}{l}\text { WFMS exceeded } \\
\text { expectations }\end{array}$ & $\begin{array}{l}\text { Extremely nervous at outset, but } \\
\text { now very positive }\end{array}$ & $\begin{array}{l}\text { Yes; an } \\
\text { explicit } \\
\text { programme }\end{array}$ \\
\hline
\end{tabular}

In summary, it is encouraging to find that the reported instances of cultural change have generally been welcomed and have been perceived to have made a positive contribution to organisational effectiveness, amongst the participating companies. This result is particularly interesting in light of the received wisdom [Cooper, 1993; Plisken et al, 1993; Tolsby, 1998] that technology-induced cultural change is likely to lead to user resistance, or even system rejection.

\section{The Nature, and Effectiveness of Cultural Change Programmes}

The discussion in this section only relates to those cases where the cultural change was either planned, or anticipated, in advance. In only two cases, see table 5, was there an explicit cultural change programme adopted; 'the programme was based upon a clear framework of cultural objectives and was sponsored by senior managers throughout the project' (5). However, another project manager (10) commented 'an explicit cultural change programme had been planned, but as it didn't get any political support, it was abandoned'. In all other instances there was no evidence of formal and explicit cultural change programmes having been adopted. When questioned about the reason for this respondents' views were well summarised by one project manager (1) who commented: 'we lack the necessary experience and expertise with regard to managing cultural change'. Whilst cultural change 
programmes were fairly rare, all interviewees acknowledged the importance of explicitly analysing the impact of the system on working practices and jobs; 'all jobs were explicitly analysed and re-designed, all job specifications were re-written' (3).

What all but one of the interviewees were agreed upon, however, was the need introduce a number of measures in addition to the implementation of a new piece of software to ensure that the cultural change was successful. Perhaps the most important of these measures was the introduction of broad training and education programmes which went far beyond basic software training $(6,10,11 \& 12)$. The active involvement of business users, from clerical staff through to senior managers, throughout the development and implementation process was also cited as an important factor (5 \& 11). Other measures included having a clear vision (2), adopting poster campaigns to reinforce important messages (12), the utilisation of customer awareness programmes (3), the introduction of 'buddy systems' where experienced users would support novice users (12), consultative committees and benchmarking programmes (11). Perhaps one of the most important, but least tangible, factors mentioned was the fact that organisational change in these companies is becoming a way of life, and consequently, employees are becoming less resistant to its impact; 'employees are now far more flexible and amenable to change' (2).

\section{Discussion: the Impact of WFMS on Organisational Culture}

Having established the impact of the introduction of WFMS technology on an organisation's culture, it is important to review the findings and contextualise them within the relevant literature. Furthermore, the implications of this study, both for the IS / IT practitioner and the researcher, are reviewed, as are the study's potential limitations.

This research makes a significant contribution as it addresses both an important new technology, the workflow management system, and an increasingly common organisational phenomenon, IT-induced cultural change, neither of which has been fully explored in the literature. More specifically, the study has established that managers perceive that WFMS technology has the potential to make significant modifications to the culture of an organisation. Moreover, no evidence has been found to suggest any user resistance, let alone system rejection, as a consequence of IT-induced cultural change. On the contrary, in most instances the systems have delivered tangible benefits to the organisation, and have been positively embraced by the users. These are particularly important finding as they demonstrate that the findings of previous studies by Tolsby [1998], Pliskin et al [1993] and Cooper [1994], which indicate that IT-induced cultural change is likely to result in user resistance and possibly system rejection, do not apply in all circumstances. It is therefore, important to explore why, in the circumstances of this study, both the introduction of the WFMS technology and the accompanying cultural change were viewed positively, from both the organisational and the user perspective, in all the participating organisations. In addressing this issue, the 'service quality' literature provides some important illuminations.

It has been recognised that the attainment of high levels of 'service quality' is critical for enhancing 'customer relationships', especially for those organisations operating in 'people- 
intensive service industries', [Lewis \& Gabrielsen, 1998]. However, 'improving service' quality in the financial services sector is predicated upon an 'an appropriate organisational culture' and 'effective systems and procedures' [Lewis, 1994: 205]. Consequently, it is likely that the introduction of WFMS is viewed positively, from the organisational perspective, as it provides an appropriate culture and effective systems for the delivery of an enhanced customer orientation. The service quality literature also provides some important insights into why the WFMS and associated organisational change might be acceptable, or even desirable, from the employees' perspective. Howcroft [1993] has noted that 'clerical staff are acutely aware of the importance of providing a quality customer service'. It has, however, also been noted that to achieve this front-line employees need to be empowered to 'demonstrate initiative and flexibility' [Lewis \& Gabrielsen, 1998]. It may well be that the introduction of WFMS has been welcomed by the employees because they have been given an appropriate mix of systems, skills and authority to deliver higher levels of customer service.

These findings offer a number of important implications for managers within the financial services sector. The reported benefits of the introduction of WFMS and the associated cultural change, should be of interest to managers, especially at a time when most are trying to improve their relationships with customers, the quality of their services and the flexibility of their staff. Furthermore, the research provides some important insights into the content and focus of a cultural change programme, to accompany the introduction of WFMS. More specifically, the importance of redesigning jobs and working practices, the re-engineering of processes, the provision of broad training and education, the need for regular and meaningful communication and the active involvement of all grades of user in the systems development process, has been established. Ultimately, this research should also be of interest to the researcher, as it has highlighted many interesting new issues, upon which future research might be based.

Research into the adoption of innovative technology, within the organisational context, is an ambitious undertaking, and therefore contains a number of inherent limitations. In particular, the potential for non-response bias in the survey exercise, the relatively small number of organisations participating in the interview phase, and the possibility of response bias associated with targeting a single managerial informant, in both the survey and interview phases. Consequently, whilst the study provides many interesting and novel insights, these potential limitations do highlight the need for follow-up studies to be conducted employing different methods, and target different populations. More specifically, follow-up research might focus upon the strength and longevity of the cultural change. It could be, for example, that in some cases changing culture was akin to 'pushing at an open door', because of the strong relationship between the WFMS-induced cultural change and the espoused organisational values. In other instances it may be that the cultural change proves to be short-lived unless further, complementary strategies are adopted to reinforce it. Follow-up research should also be targeted at the end-users of WFMS to ensure that their perceptions of impact are the same as those of their managers. 


\section{Concluding Remarks}

The work presented in this paper is of much interest in that it addresses an important area of research, which has not, to date, received the amount of attention it deserves. The results are of significance because they represent the views of managers who have played key roles in the development and implementation of WFMS technology in large and very sophisticated organisations. Consequently, the results of the survey should be of particular interest, to all organisations who are either actively developing WFMSs, or who are considering using technology. Furthermore the results should be of great interest to all academics and IT professionals who are interested in the cultural implications of the introduction of information technology. Finally, whilst the sample of managers interviewed was relatively small, the high degree of consistency in the responses of the sixteen participants suggests that they are likely to be representative of a broader constituency of views.

\section{Acknowledgements}

The authors would like to thank all those individuals who participated in this study, especially those who agreed to be interviewed, and those who helped to validate the interview schedule.

\section{References}

Amberg, M., 1996, 'Enhancing the Competitiveness of Enterprises by Applying Advanced Workflow Management Systems', European Conference on Management in Face of Knowledge Driven Competition, Porto, Portugal September.

Brown, A., 1993, Organisational Culture, London: Pitman.

Butterfield, J. and N. Pendegraft, 1996, 'Cultural Analysis in IS Planning and Management', Journal of Systems Management, March / April.

Churchill, G. A., 1991, Marketing Research Methodological Foundations, 5th edition, Orlando: Dryden Press.

Conspectus, 1996, 'Workflow and Document Management Technology', Conspectus, September.

Cooper, R. B., 1994, 'The inertial impact of culture on IT implementation', Information \& Management, Vol. 27, pp. 17-31.

Doherty, N. F. and I. Perry, 1998, The uptake and application of work flow management systems in the UK financial services sector, Journal of Information Technology, Vol. 14, pp. 149-160.

Furnham, A. and B. Gunter, 1993, 'Corporate Culture', in C. L. Cooper and I. T. Robertson (eds.) International Review of Industrial and Organisational Psychology, Chichester: Wiley.

Howcroft, J. B., 1993, 'Staff Perceptions of Service Quality in a UK Clearing Bank: Some Empirical Findings', International Journal of Service Industries Management, Vol. 4, No. 4, pp. 5-24.

Lawrence, P., 1997, The Workflow Handbook, Chichester: Wiley.

Lewis, B. R., 1994, 'Service Quality: Recent Developments in Financial Services'. in A. Meidan, B. R. Lewis, and L. Moutinho, Financial Services Marketing: A Reader, London: The Dryden Press. 
Lewis, B.R. and G.O. Gabrielsen, 1998, 'Intra-organisational Aspects of Service Quality Management: The Employees' Perspective', The Service Industries Journal, Vol. 18, No. 2, pp. 64-89.

Miles, M. B., and A. M. Huberman, 1994, Qualitative Data Analysis, Thousand Oaks: Sage Publications.

Moreton, R. and M. Chester, 1996, Transforming the Business: The IT Contribution, Maidenhead: McGraw-Hill.

Peters, T. and R. H. Waterman, 1982, In Search of Excellence: Lessons from Americas Best run Companies. New York: Harper \& Row.

Pliskin, N., Romm, T., Lee, A. and Y. Weber, 1993, 'Presumed versus actual Organisational Culture: Managerial Implications for the Implementation of Information Systems', The Computer Journal Vol. 36, No. 2, pp. 143-152.

Romm, T., Pliskin, N., Weber, Y. and A. Lee, 1991, 'Identifying organisational culture clash in MIS implementation', Information \& Management, Vol. 21, pp. 99-109.

Runkel (1990)

Sathe, V. 1985, Culture and Related Corporate Realities, Homewood: Richmond and Irwin.

Smircich, L., 1983, 'Concepts of Culture and Organisational Analysis', Administrative Science Quarterly, Vol. 28, pp. 339-35.

Sprague, R. H. and B. C. McNurlin, 1993, Information Systems Management in Practice. New Jersey: Prentice-Hall.

Strauss, A and J. Corbin, 1990, Basics of qualitative research: grounded theory procedures and techniques, Newbury Park: Sage Publications.

Stowell, F. and D. West, 1994, Client-led Design, Maidenhead: McGraw-Hill.

Thompson, K. and F. Luthans, 1990, 'Organisational Culture: a Behavioural Perspective' in B. Schneider (ed.), Organisational Culture and Climate, San Fransisco: Jossey Bass.

Tolsby, J., 1998, 'Effects of organisational culture on a large scale IT introduction effort', European Journal of Information Systems, Vol. 7, pp. 108-114.

Walton, R. E., 1989 Up \& Running: Integrating IT and the Organisation, Boston: Harvard Business School.

Williams, A., Dobson, P. and M. Walters, 1990, Changing Culture, 2nd edition, London: IPM.

Willmott, H., 1993, 'Strength is Ignorance; Slavery is Freedom: Managing Culture in Modern Organisations', Journal of Management Studies, Vol. 30, No. 4, pp. 512-552.

Yin, R. K., 1994, Case Study Research, Sage Publications: Thousand Oaks.

Zammuto, R. F. and J. Y. Krakower, 1991, 'Quantitative and Qualitative Studies of Organisational Culture', in R. Woodman and W. Pasmore, (eds.), Research in Organisational Change and Development, JAI Press. 